\title{
THE FUTURE OF
}

LOCAL

Geospatial tools

For the visualization and analysis

of local news distribution

Glaus Rinner, Ryerson University,

Andrew Komaromy, Ryerson University

April Lindgren, Ryerson University

\section{Keywords}

geographic distribution

GIS

local news

spatial point pattern analysis

\section{Abstract}

Geographic Information Systems (GIS) enable the integration, mapping, and analysis of data across numerous domains. It has been estimated that 80 per cent of all data collected by governments and businesses contain geographic references, and the news media are no exception. [read more="Read More" less="Read Less"] We will explain how we conceptualize news items as spatial data points and illustrate how GIS can be used to manage and analyze them using a sample of geographic references from local news items published in the Toronto Star newspaper. The analysis makes use of cartographic mapping for visual analysis of local news distribution and geospatial tools for quantitative-statistical analysis of emerging patterns. The objective of this paper is to illustrate how computer-based mapping tools can be used to analyze the geographic distribution of news in order to identify concentrations and gaps in local news coverage within a given area and thus better understand issues and trends in local news reporting. [/read] 


\section{$f \quad$ in $x$}

\section{Introduction}

Omputer mapping software is a standard feature of the reporter's toolkit in today's newsrooms (Herzog, 2003; Vallance-Jones \& McKie, 2009), extending the history of map use in journalism (Monmonier, 1999). Sui and Goodchild (2011) call journalism "a professional activity that is inherently embedded in space and time" (p. 1740) and remind us that one of the guiding questions for news writers is "where?" Geographic information systems (GIS) bring together statistical and spatial data in ways that allow journalists to investigate and visually convey information on everything from the association of green spaces and neighbourhood wealth to public transit access and recent patterns in city-wide home sales.

The present study moves beyond the journalists' use of computer-based mapping software for news reporting purposes to focus instead on how scholars can use GIS tools to answer questions about what, where, and why news gets covered. The mapping of geographic references from news stories and photographs can reveal different patterns of coverage by different media outlets. This research explores how GIS-based tools for visualization and point pattern analysis can be used to understand and critique the spatial distribution of local news. Combined with demographic and socio-economic data, news mapping can explain differences in coverage patterns as well as the role that news reporting plays in geographic stigmatization, citizen engagement, equitable access to information, and the shaping of a news audience's sense of place.

The paper starts with a literature review that explores the growing interest in media geography (Section 2). In Section 3 we outline how a data set representing the geography of local news coverage in the Toronto Star newspaper was assembled based on the coding of story topics and geographic references in local news stories and photos. The visualization and analysis methods explained in Section 4 include point and proportional symbol mapping; Kernel density estimation; hot spot analysis; and local indicators of spatial association. These methods are then applied to the sample data that represent the geographic footprint of the Toronto Star (Section 5). Section 6 concludes the paper with a discussion of results and limitations, and an outlook on future research.

\section{0}


Ryerson University

FCAD

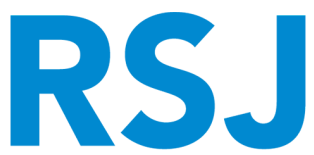

RYERSON

SCHOOL OF

JOURNALISM

\section{THE FUTURE OF}

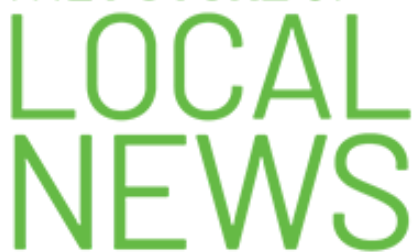

Research and Reflections

\section{ABOUT OUR \\ PUBLICATION}

This multimedia

publication, The Future of

Local News: Research and

Reflections, is the

culmination of several

years of academic research,

complemented by a year of

student journalism, an

international conference,

and a cross-Atlantic

editorial collaboration

focused specifically on the

current and future state of

local news around the

world.
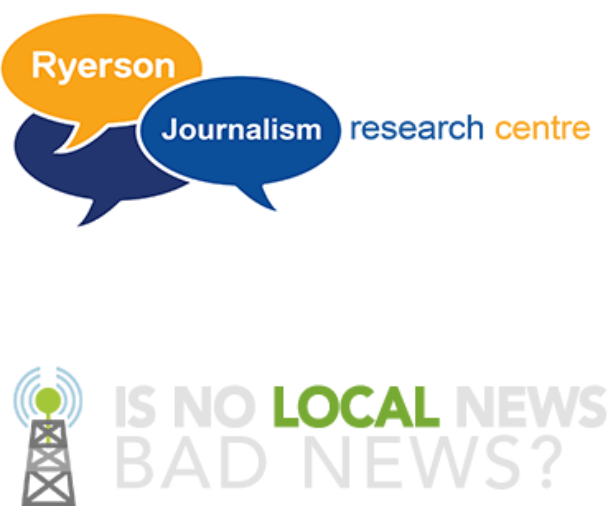

(C) 2019 The Future of Local News | Ryerson Journalism Research Centre

If you have questions or concerns, please contact the Ryerson Journalism Research Centre here.

\section{(c) $($ ) $\odot$}

This work is licensed under a Creative Commons Attribution-NoDerivs 2.5 Canada License. 